\title{
BETWEEN- AND WITHIN-PERSON VARIATION IN AFFECT AND PERSONALITY OVER DAYS AND YEARS: HOW BASIC AND APPLIED APPROACHES CAN INFORM ONE ANOTHER*
}

\author{
DANIEl K. MroczeK, AVRon SPIRo III, \\ AND DAVID M. ALMEIDA
}

Distinguishing within-person from between-person variability in personality and wellbeing constructs is important for understanding their stability and change over varying periods, from moments to decades. Regardless of whether the variation is over days or years (or seconds to decades), it is important for researchers and practitioners alike to comprehend what it means for a person to vary from himself or herself, and what it means for one person to vary from another. The current study gives two examples of within- and between-person. The first example involves two major personality traits, extraversion and neuroticism, over a 12-year longitudinal period. The second example involves negative affect in a one-week daily diary study. Researchers should be aware of the within vs. between distinction because it is at the heart of important theoretical problems in ageing and development. Practitioners should appreciate it because it can distinguish between long-term clinical trends and short-term fluctuations.

\section{Introduction}

Both personality and well-being have been at the center of various debates concerning stability and change over time (Bengtson, 1996; Costa \& McCrae, 1994; Diener, Suh, Lucas \& Smith, 1999; Larsen, 1989; Lykken \& Tellegen, 1996; Myers \& Diener, 1995; Silverstein \& Bengtson, 1994), and both are related to important physical and mental health outcomes. For example, the personality trait of neuroticism predicts onset of hypertension (Spiro, Aldwin,

Ageing International, Summer 2003, Vol. 28, No. 3, p. 260-278. 
Ward \& Mroczek, 1995), and impulsivity predicts mortality (Friedman et al., 1993). Many have studied how personality or well-being measured at a single time point is related to health. However, less is known about how change in personality or well-being is related to health. Understanding change in these constructs over years, as well as over shorter periods of time (e.g., days, weeks), can lead to meaningful insights into their roles in explaining change and variation in physical and mental health over the lifespan. Personality and psychological well-being are key constructs that display both dynamic and static qualities over varying time frames. While much is known about the static aspects, less is known about the dynamic aspects.

\section{Purpose and Objectives}

This study examined personality traits and well-being from an intra-individual approach. In particular, we were interested in two aspects of personality development, one having to do with long-term (over a decade) trait stability and change, the other with short-term (daily) fluctuations in negative affect. Although the time frames were quite different for these two types of variables, the underlying conceptual framework was the same. We were interested in partitioning intra-individual variability into two components: within-person and between-person. We approached this question primarily from the perspective of personality development. However, there are practical implications of this research. People differ reliably from one another with regard to personality traits and affective variables. These between-persons differences are essential for practitioners and researchers to grasp, because in this source of variance we observe human individuality. From a practical perspective, information about such individuality can lead to individually designed treatment and other programs. However, people also vary from themselves (Fleeson, 2001). This within-person variation is equally important to recognize, as it may give the practitioner and researcher important information about the changing states of an individual's life. For example, Eizenman, Nesselroade, Featherman and Rowe (1997) documented fluctuations in such a personality (perceived control) that predicted mortality. A systematic increase in the amount of variability in perceived control may indicate serious pathology that ultimately may bring death. Similarly, Small and Backman (1997) reported changes in cognitive functioning that were correlated with mortality five years later. Thus the issue of assessing, analyzing, and understanding intra-individual variability is not a trivial one. It may mean the difference between life and death.

\section{Conceptual Framework}

Distinguishing within-person and between-person variability is of utmost importance in understanding stability and change in personality over periods of years. Similarly, understanding within- and between-person variance is essential 
for understanding ups and downs in such constructs as affect over periods of days. Whether the variation is over days or years, it is important for both researchers and practitioners to comprehend what it means for a person to vary from him or herself, and what it means for persons to vary from one another.

Within-Person Variation. Let us define the difference between within-person and between-person variation in the context of well-being and personality research. "Within-person variation" refers to variability from occasion to occasion within a person. Occasions can be daily, weekly, monthly, yearly, every few years, or any other regular or irregular length of time. Some people are highly invariant over time on such constructs as personality traits or wellbeing. These persons are characterized by stability, and their within-person variance is zero, or near zero. Other persons show greater amounts of variability over time. There are generally two conceptual types of within-person variance that are of interest to personality and well-being researchers and relevant for practitioners. One is intra-individual change or stability. This refers to the general trend of a given person's trajectory. For example, a person's well-being may fluctuate at some regular interval (e.g., well-being is low around his or her birthday or holidays), but the general trend for that person may be characterized by a general increase in well-being over a multi-year period. The other type of variability is fluctuation around the trend. This refers to variability (or fluctuation) around the line or curve that indicates the longer-term change or stability trend. This fluctuation can be regular or cyclic (e.g., circadian rhythm) or context-driven, and is often called "intra-individual variability" (Nesselroade, 1988; 1991). Disentangling the two requires both long-term data as well as shorter-term "bursts" of measurement on the same individuals (Nesselroade \& Boker, 1994). All of the above sources of variation are systematic, not error, but of course error or noise will be present in within-person measurements as well. By assessing multiple data points over varying lengths of time, the estimates of actual change, intra-individual variability, and error become more precise and more separable.

Between-Person Variation. "Between-person variation" refers to the classic phenomenon of individual differences in a variable. For example, regardless of how much a person's well-being fluctuates from week to week, and irrespective of the rate of increase (or decrease) in well-being over a multiyear period, that person has some typical level of well-being that can differ considerably from the typical level of well-being of other people. A person's characteristic level of well-being is represented by the term between-person variation. People obviously differ from one another, and these individual differences are captured in estimates of between-person variance.

Within- and Between-Person Variance and the Data Box

Within- and between-person variance form two major cornerstones of Cattell's (1966) concept of the data box, or three-axis covariation chart. Of 
the three dimensions (or Cartesian coordinates) of the data box, persons make up one dimension, occasions a second, and variables a third. Each dimension provides essential information, but important information is also obtained by examining each dimension across the others. That is, each of the three dimensions can be combined into pairs that represent a distinct type of data and a unique way of conceptualizing research questions. For example, we can look at variability across persons on a given variable (R-technique; Cattell, 1966). This would constitute between-person variance, or simply, variance due to individual differences. We may also look at within-person variability across variables, a method known as P-technique. The P-technique historically has been the method used and referred to most often with regard to discussion of intra-individual variation. Yet the P-technique does not include the time or occasions dimension of the data box, only persons and variables. We can consider the third dimension (occasions) and look at a given person on a given variable across many occasions (S-technique; Cattell, 1966). This would constitute another type of within-person variance, different from what P-technique provides. In this sense, the data box thus provides a helpful rubric for distinguishing between- and within-person variance over time.

Although the concept of the data box is useful, it remains abstract. Thus, the concepts of within- and between-person variance can be illustrated via an analogy with weather across different cities (see also Roberts \& Pomerantz, 2002). There is obviously between-city variance in weather. Chicago's average annual temperature is colder than Rome's. In turn, Rome's average annual temperature is colder than Singapore's. These differences represent between-city variance in average temperature, analogous to between-person variance (individual differences) in average level of well-being or personality traits. However, there is within-city variance as well. Chicago is not the same temperature every day over the course of a year or even a week. Neither is Rome or Singapore. This is analogous to within-person variance, which represents the extent to which people differ from themselves. If people or cities never vary on some dimension (e.g., if Chicago is always the exact same temperature), then the within-person (or within-city) term would be zero. This is rarely the case, however. Almost always, there is some proportion of the total variance that embodies withinperson change or fluctuation. Further, this change or fluctuation should not be thought of as error variance, but as systematic variance. However, some people or cities do not vary on certain dimensions. Honolulu and other locales that are surrounded by large bodies of water usually have very low variation in temperature. Similarly, some people are extremely even-keeled with regard to affect. Certain individuals rarely get angry or upset, and main a cool, calm demeanor even through the most stressful of circumstances. Cases of low or no variability occur, just as cases of high variability do. 
Rationale for Current Study and Issues of Application

There are practical implications of understanding between and within-person variance in personality traits or well-being. Clinicians and human service professionals who work with older adults can usually quite easily observe differences between persons in relevant variables. Some people are regularly more cheerful or agreeable than others. Some display high levels of negative affect regularly, while others show little or none. Some people are reliably more active and extraverted than others.

However, people vary from themselves as well, and to different degrees (Fleeson, 2001). Again, this within-person variance can take two forms: systematic change over time (intra-individual change) or systematic fluctuation (intra-individual variability). Both are extremely relevant for practitioners. With regard to the former, decline in activity or extraversion levels over periods of months or years might signal psychopathology or even impending physical disease. As mentioned earlier, Eizenman et al., (1997) documented such personality changes (in perceived control) that are predictive of mortality. Other personality changes may also occur on the cusp of death or indicate major pathology. A systematic and seemingly permanent increase in a person's usual level of negative affect may indicate depression or some other serious psychiatric or physical disorder. With regard to the latter (intra-individual variability), greater swings in a person's usual pattern of variation may indicate problems. For example, a given Alzheimer's patient may have a low typical level of irritability. Suddenly, variability in irritability increases. An analysis of that person finds that he or she is as agreeable as usual except around dusk when irritability increases, thus increasing the person's overall intra-individual variability. This is called "sundowning" (Bliwise, 1994) and often indicates entry into late-stage Alzheimer's. Keeping track of intra-individual variability may therefore be useful in predicting who is likely to enter end-stage Alzheimer's, and therefore better inform decisions about a patient's treatment or palliative care.

Thus, within-person change in personality or well-being may be an important harbinger of pathology. Such within-person variance is unlikely to be noticeable with informal observation, so clinicians and professionals who work with older adults are encouraged to engage in systematic and regular measurements of key personality traits, behaviors, and components of well-being. This can permit detection of important changes that signal a psychological or physical problem.

This is similar to what is routine in medical practice. Blood pressure, cholesterol, and blood sugar levels are measured at regular intervals in patients, often more frequently among older adults. This allows detection of important changes that may signal some pathology. There are, of course, slight variations in such medical variables from occasion to occasion due to state variance, measurement error, etc. However, a large change over time in blood 
pressure or total cholesterol (intra-individual change) is usually reason for further tests leading to diagnosis and possibly treatment. Similarly, a large change in extraversion or global well-being may signal problems and warrant further tests and perhaps treatment. In another example, the onset of large day-to-day fluctuations in blood pressure (intra-individual variability) may indicate some underlying pathology and warrant treatment, as may the onset of large day-to-day fluctuations in negative affect or irritability.

It is true that when blood pressure or cholesterol cross certain thresholds or levels, clinicians act. They may order more tests, or even diagnose and treat. Crossing the threshold may constitute only a small change, however. Yet sometimes it is the trend or variability in a test over time that leads to a diagnosis or treatment, not just the level. Bipolar mood swings are an example of this in psychiatry.

Within-person variation often provides important baseline or background information about people, and defines what level of variability is normal for them (Fleeson, 2001). This is important from a practice perspective as well as research perspective, because it often defines stability in some dynamic system. A person may not vary much from his or her average daily level of negative emotion, or may vary quite widely from that average level. Regardless of whether the within-person variation is high or low, if the variability is roughly the same from week to week, or month to month, it implies stability or regularity in the dynamic system of negative affect. That stability may be lost due to some external life event (death of a spouse) or some internal event (a heart attack). The loss of stability may be temporary, as a perturbation, or may be permanent. In such cases, the departure from one's usual level of within-person variability may help clinicians estimate the severity of the psychological or emotional damage of the event. More importantly, external or internal events unknown to the clinician or professional can trigger changes in within-person variability in daily affect. In these instances, the change in within-person variation may be the only indicator that something has happened, and thus permit probing to determine the cause. For example, a river of water (a dynamic system) moves smoothly and predictably, just as daily variation in emotion or personality does for most people. A river may change course over the miles, or become faster or slower. Yet these are often gradual changes. Emotion or personality may show similar gradual changes over time. However, when a waterfall or rapids occur, or when a dam breaks, the dynamic system of the river is quickly and substantially altered. So it is with emotion or personality. A major life event may cause the predictable river of emotion or personality to become a waterfall. Understanding such alterations in regular patterns of emotion or personality is important for researchers and professionals alike.

We need to mention one caveat before moving on. The above exposition assumes that constructs such as emotion and personality and their measurement properties remain invariant over time. "Invariance" means that constructs 
and measures retain the same psychometric properties over multiple measurement occasions. When the spacing between measurements is not long (e.g., minutes, hours, days, weeks) it is unlikely that constructs vary with respect to measurement properties. Yet over periods of years, it is possible that certain measurement characteristics may change, or become variant. For example, the factor structure, factor loadings, or inter-factor correlations may change over time. If these properties remain invariant, then measurement equivalence holds. If it does not, this means the measure may have changed with regard to what it is assessing. Researchers should check for invariance, in particular when the measurement occasions occur over long periods of time (years). If measurement invariance arises, it is more likely when the follow-up period is long as opposed to short (days, weeks).

In the remainder of this paper, we give examples from our work using statistical procedures that allow separation of within- and between-person variability (mixed models; Bryk \& Raudenbush, 1992). Two data sets were drawn upon. One consists of older men mostly living in the Boston area; the other was a national sample of Americans aged 25 to 74 . In the former, we modeled within- and between-person variability in personality traits over a decadelong period; in the latter, we modeled within- and between-person variability in emotion over a short-term period. The two studies use very different time intervals: days versus. years. However, negative affect can and does change on a daily or even momentary basis, while personality changes much more slowly (if at all) for some people. Both time frames are important, because changes that are indicative of pathology can occur at either level. Further, results of both studies will demonstrate that people vary as much from themselves as they do from one another. This is an important message for both researchers and practitioners.

\section{Study One}

In Study One, we utilized multiple waves of data on two major personality traits (extraversion and neuroticism) that were assessed several times over a 12-year period. Extraversion and neuroticism are perhaps the best known members of the Five-Factor Model (FFM) of personality traits (Costa \& McCrae, 1994). The two traits also form the cornerstones of Eysenck's theory of personality (Eysenck \& Eysenck, 1968). A persistent controversy in personality development is whether traits stay stable or change over time (Mroczek \& Spiro, in press). If people are mostly stable, then most of the observable variance should be between-person variance. That is, if everyone stays at roughly the same score on extraversion over the years, there should be little observable within-person variance. If everyone is stable, then the only meaningful variability is captured in the differences between people. By using mixed models (Bryk \& Raudenbush, 1992), we can separate within- from betweenperson variance and see how much there is of each. 


\section{Method}

Sample

Data were from the Normative Aging Study (NAS), a longitudinal investigation of normal ageing in men founded at the Boston V.A. Outpatient Clinic in the early 1960s (Bosse', Ekerdt \& Silbert, 1984; Mroczek \& Spiro, in press). Most NAS participants are veterans, the majority having served during the World War II and Korean War eras. In 1988, the beginning of the follow-up period for this study, the age range for the 1,663 men included was 43 to 91 years $(M=63, S D=8)$.

\section{Design}

Data came from six administrations of the EPI-Q over a 12-year period. Three of the administrations occurred in 1988, 1991, and 1992 as part of mail surveys. Beginning in 1993 and continuing through 1999, the EPI-Q was mailed to each man prior to his triennial NAS biomedical exam. Therefore, the latter occasions of measurement did not occur on all men at one point in time, but rather occurred at three-year intervals beginning in 1993. Across the assessments, 1,663 men provided 5,664 measurements. One advantage of mixed models is that it permits the use of individuals who do not have data on all waves, and allows observations collected at intervals that vary both within and across persons.

\section{Measures}

Extraversion and neuroticism were assessed via the EPI-Q (Floderus, 1974), a short measure based on the Eysenck Personality Inventory (Eysenck \& Eysenck, 1968). The EPI-Q consists of 18 items, nine each for extraversion and neuroticism. Items are dichotomous and scores range from 0 to 9 for each trait. The EPI-Q has a fairly stable factor structure over time (Floderus-Myrhed, Pedersen \& Rasmuson, 1980), giving some evidence of measurement equivalence (although more sophisticated methods are available for testing measurement equivalence and invariance, those have not been applied to the EPI-Q yet).

\section{Data Analysis}

Data were arranged in "person-time," nesting measurements within persons. Thus, personality could vary over occasions within persons. This permitted us to estimate trajectories of extraversion and neuroticism over time using growth-curve modeling, which is a type of mixed model (Rogosa \& Willett, 1985; Willett, 1988). Among other parameters, mixed models yield 
estimates of random effects, which describe the extent of both within- and between-person variance (for extraversion and neuroticism in this case). Mixed models allowed us to separate how much a person varied from himself from how much he varied from others with regard to personality change. The amount that people varied from themselves is, of course, partly true or systematic variation and partly error. The inclusion of an error term is part of the model we used, allowing the estimation of a standard error around the within-person variation term. A significance test tells us if that variation is significant or simply due to error.

\section{Results and Discussion}

Table 1 shows unconditional (intercept-only) models of extraversion and neuroticism. Such models allow separation of between- and within-person variance. For each trait, each man has a certain number of measurements over a 12-year period ("occasions," in Cattell's data box terminology). So each man can vary from himself over those 12 years. Or he may not. He may remain perfectly stable, and have the exact same score on extraversion or neuroticism at each occasion. Yet most people will vary at least a bit over their measurement occasions, due to state variance and measurement error. This is within-person variance, and it is shown on the second row of Table 1. Men also can vary from each other. Average levels of extraversion or neuroticism across occasions vary from man to man, and this is between-person variance as shown on the first row of Table 1. Together, these two sources of variance make up the total amount of variation across all persons and occasions, and examining the proportion of each to the total is very useful.

These proportions make up the third and fourth rows of Table 1. For extraversion (left side of Table 1), the amount of between-person variance in personality trajectories over time is $72 \%$. The remainder is the amount that is within-person variance (plus error). So the majority of variability over time in

Table 1

\begin{tabular}{lll}
\hline \multicolumn{3}{c}{$\begin{array}{c}\text { Unconditional (Intercept-Only) } \\
\text { and Neuroticism over 12 Years }\end{array}$} \\
\hline & Extraversion & Neuroticism \\
\hline Effect & Estimate (se) & Estimate (se) \\
Between-Person Variance & $3.649(.145)^{* * *}$ & $3.626(.148)^{* * *}$ \\
Within-Person Variance & $1.419(.032) * * *$ & $1.760(.039) * * *$ \\
\hline Proportion of total var. that is between-persons: & .72 & .67 \\
Proportion of total var. that is within-persons: & .28 & .33 \\
\hline Note: $* * * \mathrm{p}<.001$ & &
\end{tabular}


extraversion is variability in average level of extraversion. People vary from one another on extraversion, and this accounts for $72 \%$ of the total variability in across all extraversion measurements. Yet, this between-person source is not $100 \%$. A considerable minority of the variation, $28 \%$, represents within-person variance. So the amount that people vary from themselves is not negligible.

To illustrate both between and within-person variation in extraversion, note Figure 1. This figure shows a collection of 10 extraversion trajectories. Each corresponds to an actual person's measurements over time, using person-level intercepts and slopes obtained from mixed models. Every line represents the regression line that best characterizes a given person's extraversion measurements. Note that some men go up, some down, and others remain stable. This illustrates within-person variation, or whether someone varies from him or herself. However, each line has a different intercept, and well as a different average level. This illustrates between-person variation.

Recall our earlier example of a person adjusting to a nursing home. Such a person may display an extraversion trajectory that declines sharply, at least at first. As that person adjusts, however, we would expect a leveling or reversal of the trend. Yet we would need to take into account that person's normal or usual level of extraversion. Hence, assessment of both within- and betweenperson variance would be essential for understanding and monitoring a patient's adjustment process, as least as tracked by personality trait measurements.

\section{Figure 1}

A collection of extraversion trajectories, each based on several occasions of measurement over 12 years

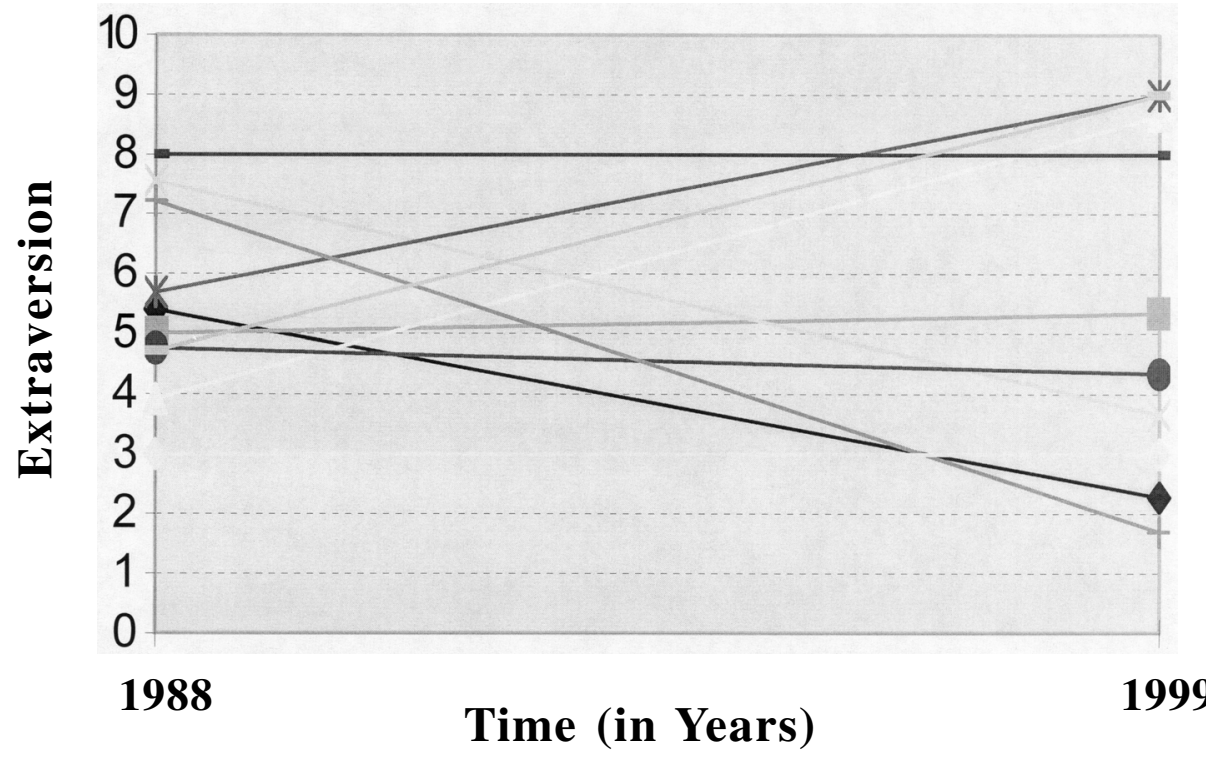


Note the right side of Table 1, which displays the within- and between variance estimates for neuroticism, along with proportions of each to the total. The between-person proportion is lower here at .67, and the within-person is higher at .33. It appears that there is more within-person malleability in neuroticism than in extraversion. At least in this sample, the individual differences in this trait do not dominate the total variability quite as much, although they surely are a very large proportion (two-thirds).

In both traits, however, we can observe considerable amounts of both within- and between-person variation. People certainly vary from one another, but they vary from themselves as well. The former accounts for most of the longitudinal variation in traits, but the latter is not so small as to be negligible, either.

\section{Study Two}

In Study Two, we assessed a major element of psychological well-being, negative affect, over an eight-day period in more than 1,000 people. Along with positive affect and life satisfaction, negative affect is considered one of three key components of well-being (Diener et al., 1999; Diener \& Diener, 1996). Unlike Study One, our focal construct in Study Two was not measured over long periods of time. Instead of occasions spread over years, measurements of negative affect were spread over days. Occasions are nested within individuals as Cattell (1966) envisioned in the data box, permitting separation of within- and between-person variance via the use of mixed models. In Study Two, we estimated the extent to which people vary from themselves on negative affect over eight days, as well as the extent to which people varied from one another in average level of negative affect over these days.

\section{Method}

Sample

Data for Study Two were from the National Study of Daily Experiences (NSDE; Almeida, Wethington \& Kessler, 2002; Mroczek \& Almeida, in press). Respondents were 1,012 adults (54.5\% women, $45.5 \%$ men) all of whom had previously participated in the Midlife in the United States Survey (MIDUS), a nationally representative telephone and mail survey of 3,032 people aged 25 to 74 , carried out in 1995-1996 by the John D. and Catherine T. MacArthur Foundation Research Network on Successful Midlife Development. Respondents were on average 47 years old.

Design

Over the course of eight consecutive evenings, respondents completed short telephone interviews about their daily experiences. The NSDE data collection 
spanned an entire year (March 1996 to March 1997) and consisted of 40 separate "flights" of interviews, with each flight representing the eight-day sequence of interviews from approximately 38 respondents. The initiation of interview flights was staggered across the days of the week to control for possible confounding between day of study and day of week. The daily telephone interviews took place in the evening of each study day. Respondents completed an average of seven of the eight interviews, resulting in a total of 7,221 daily interviews.

\section{Measures}

Our analyses made use of daily assessments of negative affect. We used an inventory of 10 items (Kessler, Andrews, Colpe, Hiripi, Mroczek, Normand, \& Walters, 2002). Respondents indicated how much of the day they experienced each negative affect item on a 0 to 4 scale. The response options were: "none of the time," "most of the time," "some of the time," "a little of the time," and "all of the time." For each day in the daily study, we took the mean of these 10 negative affect items.

\section{Data Analysis}

Again, we used mixed models to analyze these data (Bryk \& Raudenbush, 1992). Data were arranged in person-time as in Study One, but here they were in "person-days," nesting negative affect measurements within persons. Thus, affect could vary over days within persons. Most participants had between six and eight (average of seven) measurements of negative affect over the eightday period. Again, as in Study One, mixed models yielded estimates of random effects, thus describing the extent of both within- and between-person variance (for negative affect in this case). Mixed models allowed us to separate how much a person varied on negative affect from day to day (how much the person varied from him or herself) versus how much he or she varied from others in their average daily level of negative affect.

\section{Results and Discussion}

Table 2 shows an unconditional (intercept-only) model of negative affect over the eight days. Each person has an average of seven measurements over the eight-day period ("occasions"; Cattell, 1966). People will vary around their average level of negative affect over those eight days (although some may not), but they will also vary from each other in average level. As in Study One, the latter is between-person variance and it is shown on the first row of Table 2. The former is within-person variance, and it is shown on the second row of Table 2. Again, examining the proportion of each variance source to the total yields important insights. 
These proportions make up the third and fourth rows of Table 2. For negative affect, the amount of between-person variance in personality trajectories over time is .54. The remainder is within-person variance, and it is .46. So the majority of negative affect variability over the eight days is between-person variability, but it is barely a majority. The within-person portion is $46 \%$, meaning that for all practical purposes, people vary from themselves about as much as they vary from one another on daily negative affect.

It is certainly common sense that people feel greater negative affect on some days than on others. Some days carry stressors that increase negative affect, others positive events that decrease it. What mixed models add is a precise estimate of such within-person variance. Such day-to-day variability in the causes of negative affect necessarily create variability in negative affect. Tracking daily negative and positive affect in older adults, especially institutionalized adults, can help professionals understand patterns of day-today variability, and potentially lead to improved health care and service provision, thus increasing quality of life. However, such tracking also needs to take into account the between-person variance in daily negative affect. People vary from each other considerably in average level of negative affect. In Study Two, this percentage was 54\%, which is less than the $67 \%$ and $72 \%$ for the traits in Study One, but Study One assessed outcomes over a 12-year period. In an eight-day time frame, we saw almost as much between-person variance in negative affect as we saw between-person variance in personality traits over a decade (and about twice as much withinperson variance). Professionals working with older adults should take into account these considerable between-person differences, which is scientifically and practically quite interesting. Regardless of how fluctuant a given person's affect is in a given week, that person may have lower average negative affect than another person who consistently and reliably experiences high negative affect. The latter person is likely to cause more difficulties for human service professionals than the former.

Table 2

\begin{tabular}{lc}
\hline \multicolumn{1}{c}{ Unconditional (Intercept-Only) Model of Daily Negative Affect Over 8 Days } \\
\hline Effect & Estimate (se) \\
\hline Between-Person Variance & $.072(.004)^{* * *}$ \\
Within-Person Variance & $.063(.001)^{* * *}$ \\
\hline Proportion of total variance that is between-persons: & .54 \\
Proportion of total variance that is within-persons: & .46 \\
\hline Note: $* * * \mathrm{p}<.001$ &
\end{tabular}




\section{General Discussion}

We illustrated the concepts of within- and between-person variance using data that were similarly structured (multiple occasions nested within persons) but varied with regard to type of variable and, more importantly, duration of time. The examples showed that over years and over days, people vary considerably both from themselves and from one another. Both of these types of variance were considerable whether our measurements were made within a week-long or decade-long period, and researchers and practitioners should appreciate what each tells us about change within and between persons.

Within-person variance refers to change or fluctuation within a person, and tells us whether a person is stable or changing over the long-term (over years) or is more or less labile over shorter intervals (over days or weeks). Stability and change at levels of both years and days are important for those involved in treatment or in the providing of human services to older adults (or children or adolescents). A major goal of any treatment is to bring about change if someone is not healthy, or to maintain stability if a person is in good mental or physical health. For example, the depressed person is treated with the hope of bringing him or her into a state of wellness, and maintaining a long-term non-depressed state.

However, the depressed person comes to treatment bearing predispositions. Some people experience more severe depression than others, and some people experience only the mildest forms of depression, whether due to genetic factors or other internal or external circumstances. These individual differences are the heart of between-person variance, and they are important for professionals involved in treatment or in the providing of human services to older adults. Not everyone in need of treatment is equivalent, and a treatment, program or intervention that works for one type of person may not work for another.

The difference between within- and between-person variance is important for researchers and practitioners in another way as well. It can help in separating state and trait variance. However, this requires a more complex study than either of the two described above. Such a study would involve a combination of the two types of studies presented earlier; namely it would track people over long periods of time, and also obtain more micro data via intensive bursts of measurement (Nesselroade \& Boker, 1994). A multi-year longitudinal design such as that Study One above can be combined with a daily experiences design such as that in Study Two. The former can help estimate the overall trend in a given variable, such as affect or depression, whereas the latter can assess the extent to which the variable fluctuates over short periods of time. A given person in a nursing home may be steadily increasing on depression over a three-year period (the overall long-term trend in trait variance), but at times spikes up or down sharply on depression (short-term state variance). A study that combines regular measurements over the long haul, while occa- 
sionally supplementing with burst of intense daily measurements over a week or month, permits separation of trait and state variance.

Using a more complex form of the mixed models described in the previous section, we can combine yearly and daily measurements to provide a more complete picture of change and stability in both personality and emotion. The daily may be related to the yearly, and vice versa. Greater fluctuation in affect at the daily level may be related to important long-term trends in affect. If such a pattern can be established, it would be useful for researchers and practitioners alike. From a basic research perspective, relationships between micro and macro variables often shed important empirical light on theoretical issues. For example, short-term daily-level fluctuations in blood pressure may cause physical damage that raises the average level of blood pressure over the long term. This sheds scientific light on what causes long-term increases or decreases in blood pressure (or affect, depression, or extraversion). However, it also has practical implications. If a person shows such daily fluctuation, it may tip off the practitioner that long-term trends in average level may be moving in a dangerous direction, and thus take appropriate treatment action. Some preliminary research has been carried out along these lines. Eid and Diener (1999) have identified day-to-day intra-individual variability in affect as a correlate of neuroticism. They did not track neuroticism over long periods of time, but the fact that a global variable such as neuroticism was related to day-to-day variation in affect hints that studies that combine long-term and short-term information on variability are likely to yield valuable information. In future research, we intend to examine whether day-to-day affect variability (as assessed from diary studies) predicts not only level but also change in neuroticism or other personality traits, in addition to level and change in wellbeing. The mixed models we used above will allow the testing of a wide array of global and daily-level variables as predictors of multi-year change in personality and well-being.

\section{Relevance for Practitioners}

We have alluded to the relevance of the concepts discussed herein for practitioners who work directly with older adults. Let us offer two specific examples. One practical use of assessing and analyzing within-person variation is to determine whether and how quickly one is adapting to a transition or stressor. Emotions and even personality can undergo change as a person makes a life transition or deals with major stressor, and tracking within-person variance can assist professionals in determining when or if adaptation is occurring. A person whose spouse has just died may experience a large increase in negative affect or even the personality trait neuroticism (which is highly predictive of negative affect) in the period following the death. Such an increase in negative affect or neuroticism may be temporary, and longitudinal tracking may show that after a period of recovery, levels of negative affect or neuroti- 
cism return to normal for that individual. In other words, adaptation has occurred. Mroczek and Spiro (in press) recently provided evidence for this in a sample of older men. They showed that the death of a spouse was related to higher levels of neuroticism in the year following the event. However, in the 10 years after, neuroticism decreased at a much faster rate among widowers than persons who did not experience the death of a spouse. These faster declines in neuroticism are a likely indicator of recovery and adaptation. Neuroticism levels rise after the death, but then return to typical level. We can actually track adaptation as it occurs in time by modeling within-person variation.

In another practical example, new nursing home residents almost always undergo a stressful period of transition as they adapt to the residence. Various emotions are likely to change during this transition, as may certain personality traits. If baseline measurements of emotion and personality are obtained in the period before the move to the nursing home, then tracking can occur postmove. Significant changes from baseline (in the negative direction, e.g., higher negative affect) are likely to indicate that the person is in a stressful transition. However, when the tracked emotions or personality traits show movement back toward baseline levels, we may be able to infer that adaptation is happening. If so, this would be enormously useful for tracking the pace of adaptation to any number of life events relevant to older adults, such as adjusting to disabilities (vision loss, physical immobility), losses of friends and family, moves to new residences, or major changes in health or functional status. Tracking adaptation via statistical models that allow estimation of the rate of within-person change could prove quite useful to practitioners and other professionals who work directly with older adults.

\section{Caveats, Limitations, and Unanswered Questions}

We have faith in the ability of these techniques to assist practitioners, yet we are aware that daily or multiple daily monitoring of the type we are advocating is labor-intensive and time-consuming. Many organizations may not have the staff or resources to carry out this kind of monitoring if the efficacy and benefits are not clear. More applied research is required to make such a case (or show that such monitoring is not needed). Yet the results of recent studies such as those by Eizenman et al. (1996) and Small and Backman (1997) show that regular monitoring of cognitive and personality variables may predict mortality. This may be a compelling reason in and of itself to engage in regular tracking of such variables.

There is also the issue of how regular should regular tracking be? For personality and possibly cognitive variables, the required time frame will likely be longer than for mood variables. Researchers should collaborate with practitioners to define appropriate windows of observation for measuring and tracking change over time. Perhaps as importantly, decision rules should be devel- 
oped for determining when a change worthy of attention has occurred. This goes back to the issue of separating fluctuation, noise, and true change. Again, researchers and practitioners should work together to identify when an important change in mood, personality, or cognitive variables has happened. False alarms may cause a patient to undergo expensive and unpleasant testing. Decision trees based on empirical data may help to increase the hit rate and minimize both false positives and false negatives.

\section{Conclusion}

Researchers need to be aware of the within- and between-person distinction because it is at the heart of important theoretical problems in ageing and development, and practitioners need to appreciate it because it can distinguish between long-term clinical trends and short-term fluctuations. Persons certainly differ in their average levels of particular personality traits or major affect dimensions, but we showed that persons also differ in rates of change in major personality traits and affect dimensions. Figure 1 illustrated this by showing actual personality trajectories differing in terms of level (between-person variance) and rate of change (within-person variance). We have perhaps belabored the point in emphasizing the distinction between these two sources of variance, but the distinction between individual differences and intra-individual differences is fundamental to gerontology as a science (Nesselroade, $1988,1991)$, as well as to gerontology as a practice.

\section{Biographical Notes}

Corresponding author: Dan Mroczek, Fordham University, Department of Psychology, Dealy Hall, 441 East Fordham Road, Bronx, NY, 10458. Email: mroczek@ fordham.edu.

Acknowledgments: This work was supported by grants from the National Institute on Aging (R01AG18436 and R03-AG16054) to Dan Mroczek, and by grants from the National Institute of Mental Health (R03-MH19734) and the National Institute on Aging (R01-AG16731) to Dave Almeida. Support was also provided by the John D. and Catherine T. MacArthur Foundation Research Network on Successful Midlife Development. Data used in Study One were collected via NIH grants to Carolyn M. Aldwin (R01-AG13006), Michael R. Levenson (R01-AA08941), and Raymond Bosse' (R01-AG02237), and by the Medical Research Service and the Health Services Research and Development Service of the Department of Veterans Affairs. The V.A. Normative Aging Study (NAS) is supported by the Cooperative Studies Program/ERIC, U.S. Department of Veterans Affairs, and is a research component of the Massachusetts Veterans Epidemiology Research and Information Center (MAVERIC).

Daniel K. Mroczek, Ph.D., is Associate Professor of Psychology at Fordham University in New York City. He received his Bachelor's Degree from Loyola University Chicago and his Ph.D. from Boston University. He also completed an NIMH postdoctoral fellowship at the Survey Research Center of the Institute for Social Research at the University of Michigan.

Avron Spiro III, Ph.D., is Research Scientist in the Massachusetts Veterans Epidemiology Research and Information Center (MAVERIC) in the V.A. Boston Healthcare System. He is also Assistant Professor of Epidemiology and Biostatistics, Boston University School of Public Health. He received his Bachelor's Degree from Emory University and his Ph.D. from Penn State University. 
David M. Almeida, Ph.D., is Associate Professor of Family Studies and Human Development at the University of Arizona. He received his Bachelor's Degree from California State University, Northridge and his Ph.D. from the University of Victoria. He also completed an NIMH postdoctoral fellowship at the Survey Research Center of the Institute for Social Research at the University of Michigan. In January, 2004, he will join the faculty of Human Development and Family Studies at Penn State University.

\section{References}

Almeida, D. M., Wethington, E., \& Kessler, R.C. (2002). The Daily Inventory of Stressful Experiences (DISE): An Interview-Based Approach for Measuring Daily Stressors. Assessment, 9, 41-55.

Bengtson, V.L. (1996). Continuities and discontinuities in intergenerational relationships over time. In V.L. Bengtson (Ed.), Adulthood and aging: Research on continuities and discontinuities (pp. 271-303). New York: Springer.

Bosse', R. Ekerdt, D. \& Silbert, J. (1984). In S.A. Mednick, M. Harway \& K.M. Finello (Eds.), Handbook of longitudinal research: Vol. 2. Teenage and adult cohorts (pp. 273-289). New York: Praeger.

Bliwise, D.L. (1994). What is sundowning? Journal of the American Geriatrics Society, 42, 1009-1011.

Bryk, A.S. \& Raudenbush, S.W. (1992). Hierarchical linear models in social and behavioral research: Applications and data analysis methods. Newbury Park, CA: Sage.

Cattell, R.B. (1966). The data box: Its ordering of total resources in terms of possible relational systems. In R.B. Cattell (Ed.), Handbook of multivariate experimental psychology. Chicago: Rand-McNally.

Costa, P.T. \& McCrae, R.R. (1994). Set like plaster? Evidence for the stability of adult personality. In T.F. Heatherton \& J.L. Weinberger (Eds.), Can personality change? (pp. 21-40). Washington, DC: American Psychological Association.

Diener, E. \& Diener, C. (1996). Most people are happy. Psychological Science, 7, 181-185.

Diener, E., Suh, E.M., Lucas, R.E., \& Smith, H.L. (1999). Subjective well-being: Three decades of progress. Psychological Bulletin, 125, 276-302.

Eid, M. \& Diener, E. (1999). Intraindividual variability in affect: Reliability, validity, and personality correlates. Journal of Personality and Social Psychology, 76, 662-676.

Eizenman, D.R., Nesselroade, J.R., Featherman, D.L \& Rowe, J.W. (1997). Intraindividual variability in perceived control in an older sample: The MacArthur successful aging studies. Psychology \& Aging, 12, 489-502.

Eysenck, H.J. \& Eysenck, S.B.G. (1968). Manual for the Eysenck Personality Inventory. San Diego, CA: Educational and Industrial Testing Service.

Fleeson, W. (2001). Toward a structure- and process-integrated view of personality: Traits as density distributions of states. Journal of Personality and Social Psychology, 80, 1011-1027.

Floderus, B. (1974). Psychosocial factors in relation to coronary heart disease and associated risk factors. Nordisk Hygienisk Tidskrift, Supplementum 6.

Floderus-Myrhed, B., Pedersen, N. \& Rasmuson, I. (1980). Assessment of heritability for personality, based on a short-form of the Eysenck Personality Inventory: A study of 12,898 twin pairs. Behavior Genetics, 10, 153-62.

Friedman, H.S., Tucker, J.S., Tomlinson-Keasey, C., Schwartz, J.E., Wingard, D.L. \& Criqui, M.H. (1993). Does childhood personality predict longevity? Journal of Personality and Social Psychology, 65, 176-185. 
Kessler, R.C., Andrews, G., Colpe, L., Hiripi, E., Mroczek, D.K., Normand, S.-L., Walters, E.E. \& Zavalavsky, A. (2002). Short Screening Scales to Monitor Population Prevalences and Trends in Nonspecific Psychological Distress. Psychological Medicine, 32, 959976.

Larsen, R.J. (1989). A process approach to personality psychology: Utilizing time as a facet of data. In D.M. Buss \& N. Cantor (Eds.), Personality psychology: Recent trends and emerging issues (pp. 177-193). New York: Springer.

Lykken, D. \& Tellegen, A. (1996). Happiness is a stochastic phenomenon. Psychological Science, 7, 186-189.

Mroczek, D.K. \& Spiro, A., III (in press). Modeling Intraindividual Change in Personality Traits: Findings from the Normative Aging Study. Journal of Gerontology: Psychological Sciences.

Mroczek, D.K. \& Almeida, D.M. (in press). The effects of daily stress, age, and personality on daily negative affect. Journal of Personality.

Myers, D.G. \& Diener, E. (1995). Who is happy? Psychological Science, 6, 10-19.

Nesselroade, J.R. (1988). Sampling and generalizability: Adult development and aging issues examined within the general methodological framework of selection. In K.W. Schaie, R.T. Campbell, W.M. Meredith, \& S.C. Rawlings (Eds.), Methodological issues in aging research. New York: Springer.

Nesselroade, J.R. (1991). Interindividual differences in intraindividual change. In L.M. Collins \& J.L. Horn (Eds.), Best methods for the analysis of change, (pp. 92-105). Washington, DC: American Psychological Association.

Nesselroade, J.R. \& Boker, S.M. (1994). Assessing constancy and change. In T.F. Heatherton \& J.L. Weinberger (Eds.), Can personality change? (pp. 121-148). Washington, DC: American Psychological Association.

Roberts, B.W. \& Pomerantz, E. M. (2002). Re-Examining the Person-Situation Debate through the Lens of Personality Development. Unpublished Manuscript, University of Illinois, Champaign, IL.

Rogosa, D. \& Willett, J.B. (1985). Understanding correlates of change by modeling individual differences in growth. Psychometrika, 50, 203-228.

Silverstein, M. \& Bengtson, V.L. (1994). Does intergenerational social support influence the psychological well-being of older parents? The contingencies of declining health and widowhood. Social Science and Medicine, 38, 943-957.

Spiro, A., III, Aldwin, C.M., Ward, K. \& Mroczek, D.K. (1995). Personality and the incidence of hypertension among older men: Longitudinal findings from the Normative Aging Study. Health Psychology, 14, 563-569.

Small, B.J. \& Backman, L. (1997). Cognitive correlates of mortality: Evidence from a population-based sample of very old adults. Psychology \& Aging, 12, 309-313.

Willett, J.B. (1988). Questions and answers in the measurement of change. In E.Z. Rothkopf (Ed.), Review of research in education, Vol. 15 (pp. 345-422). Washington, DC: American Education Research Association.

* Invited paper. Revised manuscript accepted for publication in March, 2003. Action Editor: P.S. Fry. 
Copyright of Ageing International is the property of Transaction Publishers and its content may not be copied or emailed to multiple sites or posted to a listserv without the copyright holder's express written permission. However, users may print, download, or email articles for individual use. 